\title{
Crise Pandêmica E A Violação Aos Direitos Dos Consumidores: Os Marcos Regulatórios Emergentes Do Direito Do Consumidor
}

\author{
Lúcia Souza d'Aquino* \\ Universidade Federal do Rio Grande do Sul, Programa de Pós-Graduação em Direito, \\ Porto Alegre-RS, Brasil. \\ 2) http://orcid.org/oooo-0002-0838-3566 \\ Luana Mathias Souto** \\ Pontifícia Universidade Católica de Minas Gerais, Programa de Pós-Graduação em \\ Direito, Belo Horizonte-MG, Brasil. \\ iD http://orcid.org/oooo-0002-6961-0187 \\ Guilherme Mucelin*** \\ Universidade Federal do Rio Grande do Sul, Programa de Pós-Graduação em Direito, \\ Porto Alegre-RS, Brasil. \\ http://orcid.org/0000-0003-3709-6539
}

Resumo: O presente estudo busca refletir sobre os impactos do marco regulatório emergencial criado para as relações consumeristas, que foram severamente abaladas pelo isolamento social, ancorado em revisão bibliográfica sobre o tema e dialogando com dados relativos ao atual cenário imposto pela pandemia de COVID-19 às relações de consumo. Com base na análise dos marcos regulatórios criados para essas relações, observou-se a factualidade da teoria do estado de exceção, desenvolvida por Giorgio Agamben (2004; 2007), quando as escolhas promovidas para reverter os efeitos deletérios da pandemia beneficiam apenas um dos polos da relação consumerista e que, por consequência, fragiliza, ainda mais, os consumidores, escancarando suas condições de homens sacros, vidas nuas de direitos. As reflexões ora apresentadas, por fim, encaminham à conclusão de que a pandemia de COVID-19 e os novos marcos regulatórios de Direito do Consumidor por ela criados apenas potencializam as vulnerabilidades daqueles que já são, sob os diversos pontos de vista apresentados neste artigo, vulneráveis.

Palavras-chave: COVID-19. Estado de Exceção. Direito do Consumidor. Vulnerabilidade.

* Doutora em Direito pela Universidade Federal do Rio Grande do Sul. E-mail: luciasdaquino@gmail.com

*** Doutoranda e Mestre em Direito Público pela Pontifícia Universidade Católica de Minas Gerais. Email: luana.mathias.souto@gmail.com

*** Doutorando e mestre em Direito pela Universidade Federal do Rio Grande do Sul (UFRGS). Bolsista CAPES. E-mail: guilherme.mucelin@ufrgs.br

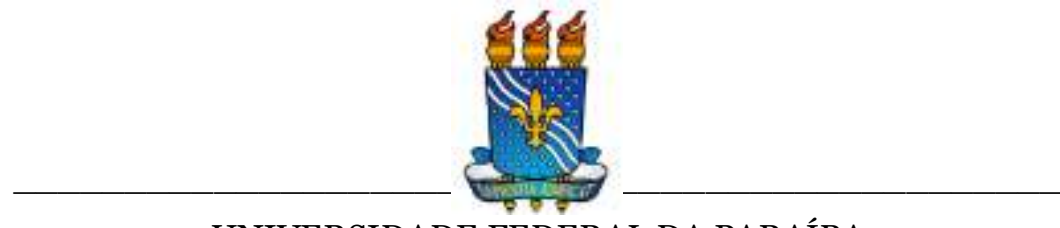

UNIVERSIDADE FEDERAL DA PARAÍBA

Programa de Pós-Graduação em Ciências Jurídicas

DOI: https://doi.org/10.22478/ufpb.1678-2593.2020v19n42.54271 


\title{
Crise Pandêmica E A Violação Aos Direitos Dos Consumidores: Os Marcos Regulatórios Emergentes Do Direito Do Consumidor'
}

\author{
Lúcia Souza d'Aquino
}

\section{Luana Mathias Souto²}

\author{
Guilherme Mucelin3
}

\section{INTRODUÇÃO}

São os momentos de crise, muito mais do que os de normalidade, que definem o curso da humanidade. A Grande Depressão de 1929 criou nova forma de relacionamento entre a economia e o Estado, redefinindo o cenário pré-existente. A Segunda Guerra Mundial, muito mais do que os anteriores períodos de paz, definiu o (des)valor da vida ou, na acepção de Hannah Arendt (1999), apresentou a banalização do mal. Quando a ordem se rompe, não apenas o caos nasce, mas toda uma nova forma de viver, de pensar e de governar também é criada.

O caos não é fato alheio ao Direito, muito pelo contrário: o Direito nasce do caos, ou melhor, do estado de natureza, onde reinava a guerra de todos contra todos, na acepção dos contratualistas. Para superar esse estágio inicial da vida em sociedade, o Direito se vale da força e da violência para fundar a ordem, estabelecer regras de boa

\footnotetext{
${ }^{1} \mathrm{O}$ presente trabalho foi realizado com apoio da Coordenação de Aperfeiçoamento de Pessoal de Nível Superior - Brasil (CAPES)

2 Bolsista PROEX CAPES/Taxa.

3 Bolsista Capes.
} 
Crise Pandêmica E A Violação Aos Direitos Dos Consumidores: Os Marcos...

convivência e harmonia entre todos e prevenir o uso individual da força.

Entretanto, invariavelmente, momentos de normalidade são afetados por situações anormais: crises econômicas, políticas, humanitárias e agora sanitárias. Quando tais fatos ocorrem, o Estado de Direito também está preparado para eles. Assim, no presente estudo será realizada breve análise sobre o sistema constitucional de crises, mecanismo inscrito no Estado de Direito desde o seu nascedouro e que permite que os momentos excepcionais sejam revertidos e a ordem restabelecida. $\mathrm{O}$ estado de exceção, portanto, é a figura jurídica que permite isso e, na acepção de Carl Schmitt (1968), poderá ser constitucional ou inconstitucional, quando da eminência de uma Ditadura Soberana. Giorgio Agamben (2004), por sua vez, realizando sua arqueologia jus filosófica, afirmará que também é possível que esse instituto se subdivida em declarado ou não declarado.

Com a atual pandemia de COVID-19, contudo, uma potencial nova forma de se observar tal instituto emana da instalação do estado de calamidade pública como ferramenta de enfrentamento da pandemia e, tecnicamente, poder-se-ia dizer que há um estado de exceção subdeclarado, uma vez que foge das hipóteses apresentadas pelo sistema constitucional de crises, mas que ainda assim relativiza direitos. Utilizando, portanto, do Direito do Consumidor como objeto de estudo, questiona-se: diante da crise pandêmica, que radicalizou as atuais formas de interação social, o que terá sido criado neste ramo do Direito durante a pandemia de coronavírus e a vigência de um estado de exceção subdeclarado? Para responder a esta questão a análise sobre o sistema constitucional de crises, a partir de revisão bibliográfica sobre o tema, se alia à análise sobre as diretrizes emergenciais criadas no Direito do Consumidor para combater os efeitos econômicos nefastos da imposição do isolamento social. 


\section{DIREITO E CRISE: A REORGANIZAÇÃO JURÍDICA FRENTE AO CAOS PANDÊMICO}

Dentro da ordem constitucional existe um sistema paradoxo em si que para restaurar a ordem, suspende a lei. Trata-se do sistema constitucional de crises, que, dentro de suas variantes, permite, por meio da própria Constituição, que, em momentos de crise, esta seja suspensa até que a anormalidade seja cessada. O embrião desse modelo advém da República Romana quando o Senado emitia um sen atus consultum ultimum, em que autorizava a intervenção de um ditador em Roma que, durante determinado período, podia realizar o que se fizesse necessário para eliminar a ameaça. Chamava-se a isto de Ditadura Comissária, na qual "o ditador tinha apenas uma comissão, como conduzir a guerra, reprimir uma rebelião, reformar o Estado ou instituir uma nova organização dos poderes públicos4." (SCHMITT, 1968, p. 58, tradução nossa). Entretanto, ele "não estava ligado às leis e era uma espécie de rei, com poder ilimitado sobre a vida e a morte5." (SCHMITT, 1968, p. 34, tradução nossa).

Já na Modernidade, com o Decreto de 8 de julho de 1791, da Assembleia Constituinte Francesa, a ideia de suspensão da ordem vigente para seu próprio restabelecimento é introduzida pela primeira vez no Estado de Direito, por meio da figura do état de siège ou estado de sítio (AGAMBEN, 2004).

O estado de sítio permite que, por meio de decreto presidencial, sejam suspensos os direitos de livre locomoção; de inviolabilidade da correspondência, do sigilo das comunicações; da liberdade de imprensa e de reunião; de inviolabilidade do domicílio; e, de propriedade diante das hipóteses de comoção grave de repercussão

4 "El dictador tenía tan solo una comisión, como conducir la guerra, reprimir una rebelión, reformar el Estado o instituir una nueva organización de los poderes públicos."

5 "No estaba ligado a las leyes y era una especie de rey, con poder ilimitado sobre la vida y la muerte." 
nacional ou ocorrência de fatos que comprovem a ineficácia de medida tomada durante o estado de defesa (BRASIL, 1988). Também poderá promover a suspensão de "toda e qualquer garantia constitucional que constar do decreto presidencial, e for autorizada pelo Congresso Nacional” (CARVALHO, 2012, p. 1289), quando a situação de fato for a declaração de estado de guerra ou resposta a agressão armada estrangeira (BRASIL, 1988).

Semelhante ao estado de sítio é a Martial Law, aplicável aos países anglo-saxões, como o Reino Unido e os Estados Unidos, em que, diante das hipóteses de guerra externa ou grave ameaça, permite-se “[a] supressão da divisão de poderes e a substituição pelo mero comando do comandante militar. Também em caso de motim pode ser proclamada [...], se existir perigo imediato à segurança pública e se já não forem suficientes os tribunais ordinários"6 (SCHMITT, 1968, p. 224).

No Direito brasileiro, por sua vez, sob a vigência da Constituição da República de 1988 (CRFB/88), além do estado de sítio, tem-se o estado de defesa como mecanismo excepcional de defesa do Estado e das instituições democráticas, que, nos termos do art. 136 da CRFB/88, permite ao Presidente da República emitir decreto com a finalidade de preservar ou prontamente restabelecer, em locais restritos e determinados, a ordem pública ou a paz social ameaçada por grave e iminente instabilidade institucional ou atingidas por calamidades de grandes proporções na natureza (BRASIL, 1988).

Diante do estado de defesa, o decreto presidencial deverá apresentar o seu tempo de duração, que não poderá ser superior a 30 dias, podendo ser prorrogado uma única vez por igual período se persistirem as razões de sua decretação, nos termos do artigo 136, parágrafo $1^{\mathrm{o}}$, da $\mathrm{CRFB} / 88$. O decreto presidencial, por sua vez, também deve indicar as áreas de abrangência da vigência da medida

6 “[...] la supresión de la división de poderes y su sustitución por el mero mando del comandante militar. También en caso de motín puede ser proclamada [...], si existe un peligro inmediato para la seguridad pública y ya no son suficientes los tribunales ordinarios." (tradução livre dos autores) 
excepcional e as medidas coercitivas a vigorarem, diante da calamidade pública, poderão restringir os diretos de reunião, ainda que exercida por associações; o sigilo de correspondência; o sigilo de comunicação telegráfica e telefônica e; a ocupação e uso temporário de bens e serviços públicos (BRASIL, 1988).

Todas essas variáveis ora descritas constituem o que se denomina de estado de exceção constitucional declarado, quando, sob a vigência da Constituição, suspende-se a lei.

Adverte-se, contudo, que existe também a possibilidade de um estado de exceção declarado, mas inconstitucional7, presente nas Ditaduras, que suspendem a lei de forma ilegítima, quando aquele que assume o poder o faz mediante golpe de Estado. Esses casos diferem da Ditadura Comissária e, portanto, recebem o nome de Ditadura Soberana ou apenas Ditadura (SCHMITT, 1968). Exemplo dessa situação é o Ato Institucional n. 5 instaurado no Brasil durante a Ditadura Civil-Militar de 1964, que suprimia direitos e garantias fundamentais de forma inconstitucional, pois a aparência constitucional criada pelos militares era ilegítima, já que se tratou de assunção de poder mediante golpe de Estado.

Para além das duas vertentes (constitucional e inconstitucional) do estado de exceção declarado, ainda existe o estado de exceção não declarado, que surge dentro da análise sobre o sistema constitucional de crises realizada por Giorgio Agamben (2004; 2007), a partir do alerta feito por Walter Benjamin, na obra 'O anjo da História' (2012), em que informa que a exceção se tornou a regra - conclusão a que chega após sua observação do avanço totalitário na Europa no século $\mathrm{XX}$.

Explorando os trabalhos de Walter Benjamin, Carl Schmitt, Hannah Arendt, Jacques Derrida e Michel Foucault, Giorgio Agamben (2004; 2007) avalia que o estado de exceção sob a perspectiva

7 É inconstitucional, pois não observa os princípios da necessidade e temporalidade que justificam o estado de exceção constitucional (SANTOS, 1981), já que seu “intuito [é] de reprimir simples divergências político-partidárias [...] voltada apenas para coibir adversários políticos e sustentar os detentores do poder e os interesses das classes dominantes aliadas às oligarquias nacionais [...]." (SILVA, 2014, p. 774). 
biopolítica $^{8}$ coexiste com o Estado de Direito, em sua forma não declarada, quando, independente da ocorrência da situação caótica, compita ao soberano suspender a lei como ato ordinário aplicável apenas a determinados corpos, aos quais ele denomina de homo sacer ${ }^{9}$, vidas nuas de direitos, homens sacros, cuja vida é "matável" e "insacrificável” (AGAMBEN, 2004; 2007).

Tal empreitada seria possível, a partir da análise de Giorgio Agamben (2004), porque no sintagma força de lei, desenvolvido por Jacques Derrida (2007) que, em síntese, decorre de uma análise de 'Crítica da violência: crítica do poder' (1986), de Walter Benjamin, o direito é violência, é a institucionalização da violência existente no estado de natureza, onde prevalecia a guerra de todos contra todos. É violência porque proíbe as violências individuais e as monopoliza enquanto única autoridade a poder exercê-la, "esse monopólio não tende a proteger determinados fins justos e legais (Rechtszwecke), mas o próprio direito." (DERRIDA, 2007, p. 78).

Assim, o estabelecimento de um sistema constitucional de crises é a violência mantenedora que conserva a violência que funda o Estado de Direito, pois "a própria violência da fundação ou da instauração do direito [...] deve envolver a violência da conservação do

\footnotetext{
8 "Concretamente, esse poder sobre a vida desenvolveu-se a partir do século XVII, em duas formas principais; que não são antitéticas e constituem, ao contrário, dois pólos de desenvolvimento interligados por todo um feixe intermediário de relações. Um dos pólos, o primeiro a ser formado, ao que parece, centrou-se no corpo como máquina: no seu adestramento, na ampliação de suas aptidões, na extorsão de suas forças, no crescimento paralelo de sua utilidade e docilidade, na sua integração em sistemas de controle eficazes e econômicos - tudo isso assegurado por procedimentos de poder que caracterizam as disciplinas: anátomo-política do corpo humano. O segundo, que se formou um pouco mais tarde, por volta da metade do século XVIII, centrou-se no corpo-espécie, no corpo transpassado pela mecânica do ser vivo e como suporte dos processos biológicos: a proliferação, os nascimentos e a mortalidade, o nível de saúde, a duração da vida, a longevidade, com todas as condições que podem fazê-los variar; tais processos são assumidos mediante toda uma série de intervenções e controles reguladores: uma bio-política da população. [...] caracteriza um poder cuja função mais elevada já não é mais matar, mas investir sobre a vida, de cima a baixo." (FOUCAULT, 1985, p.131).

9 "[...] toda sociedade - mesmo a mais moderna - decide quais sejam os seus "homens sacros". [...] No novo horizonte biopolítico dos estados de soberania nacional necessariamente ao interior de toda vida humana e de todo cidadão. A vida nua não está mais confinada a um lugar particular ou em uma categoria definida, mas habita o corpo biológico de cada ser vivente." (AGAMBEN, 2007, p. 146).
} 
direito [...] e não pode romper com ela." (DERRIDA, 2007, p. 89, grifo no original). E, por isso, seria legítimo avocar o estado de exceção declarado e atacar direitos fundamentais como mecanismo de se restabelecer a ordem.

O problema que Giorgio Agamben (2004; 2007) está a denunciar não é o uso da violência mantenedora como forma de prevenção da violência fundante, porque isto estaria inscrito nas bases do Estado e da lei, mas sim o fato de que o estado de exceção, enquanto violência consevadora, "não cessa de enfraquecer a violência fundadora que ela representa. Ela se destrói, portanto, por ela mesma, no curso desse ciclo" (DERRIDA, 2007, p. 127) e, por isso se falaria em uma permanência da suspensão da lei ou do estado de exceção (BENJAMIN, 2002), principalmente, quando em momentos mais extremos houve a indiscernibilidade entre violência fundadora $\mathrm{e}$ conservadora, como ocorreu durante o período nazista (DERRIDA, 2007; AGAMBEN, 2004), que tanto espanto causou a Walter Benjamin $^{10}$.

Em face da atual pandemia desencadeada pela disseminação do vírus causador da COVID-19, decretou-se estado de calamidade pública, mecanismo que garante a suspensão do cumprimento das metas fiscais e permite ao chefe do Executivo que, por meio de decretos, medidas referentes às finanças públicas sejam tomadas para conter a disseminação da doença. $\mathrm{O}$ estado de calamidade pública é acionado, portanto, quando os prejuízos causados pelos desastres acarretam comprometimento substancial da capacidade de resposta do Poder Público (BRASIL, 2010), o que é o caso da pandemia, diante de seu alto potencial de disseminação e contaminação.

A instituição do estado de calamidade pública, contudo, por emanar do Decreto $\mathrm{n}^{0}$ 7.257/2010 não tem o condão necessário, assim como o teria o estado de defesa ou o estado de sítio, para suspender a

\footnotetext{
${ }^{10}$ Walter Benjamin foi filósofo judeu-alemão e escreveu 'O anjo da história' nos anos inciais de vigência do regime nazista alemão. Em 1940, logo após sua publicação e já no exílio, Walter Benjamin prefere o suicídio a ser entregue a Gestapo, acrônimo em alemão usado para designar a Polícia secreta do Estado, que durante o período nazista atuou como polícia política.
} 
Constituição, local por excelência onde os direitos fundamentais encontram guarida. Entretanto, a realidade fática existente em face da pandemia deflagra o uso extraordinário, pois extrapola seus limites, da suspensão ordinária, pois permitida pelo decreto do estado de calamidade pública para que outros direitos também sejam, na prática, suspensos, como uma espécie de danos colaterais necessários para se conter a doença. Assim, cria-se um espaço anômico, em que o soberano é "o ponto de indiferença entre violência e direito, o limiar em que a violência transpassa em direito e o direito em violência." (AGAMBEN, 2007, p. 38). Sendo, portanto, a emanação de uma espécie de estado de exceção subdeclarado.

Sua dimensão de declaração advém do fato de que é a suspensão manifesta da lei, uma vez que se justifica no Decreto que lhe dá origem. Entretanto, não condiz com as formas de estado de exceção declarado, acima descritas, pois não é proveniente do sistema constitucional de crises, e sim, de norma infraconstitucional. Assim, ao existir, conforme será observado mais a frente, limitações significativas aos direitos dos consumidores, sob a justificativa da crise pandêmica, o que se tem diante desse estado de coisas, é a emanação da teoria de estado de exceção desenvolvida por Giorgio Agamben (2004; 2007); de um estado de exceção não declarado. Desta forma, a relativização de direitos sofrida pelo Direito do Consumidor em face do estado de calamidade pública se afilia à subdeclaração, constituindo-se, portanto, em nova forma de exceção.

Quando, então, nomos e anomia se tornam indiscerníveis, pois coincidem-se em uma mesma pessoa, "o sistema jurídico-político transforma-se em uma máquina letal" (AGAMBEN, 2004, p. 130-131), permitindo ao soberano indiscriminadamente decidir sobre quem vive e quem morre. Assim, "a figura da exceção, em determinadas circunstâncias, permite, [...] a suspensão do direito sobre certas pessoas ou grupos, transformando a sua vida em vida nua, ou seja, vida vulnerável, facilmente controlável.” (WERMUTH; CORREIO, 2017, p. 15).Dessa forma, sob a perspectiva agambeniana, os judeus durante o 
Holocausto e os detentos de Guantánamo eram homo sacer, pois suas vidas estavam nuas de direito, quando competia ao soberano, no caso as ordens do Führer, ${ }^{11}$ durante o período nazista e as ordens executivas estadunidenses pós 11 de setembro de 2001, decidir sobre o valor da vida em um espaço anômico de Direito (AGAMBEN, 2007).

Em "Estado de Exceção e a genealogia do poder", por sua vez, Giorgio Agamben (2014) resgata a possibilidade de existência de muitos outros homens sacros, outras formas de vida inscritas nessa sacralidade que pela inclusão/exclusão do Direito se tornam nuas em direitos, a partir da normalização/constitucionalização de algo que não é.

\section{EXCEPCIONALIDADE E A VIDA NUA NO MERCADO DE CONSUMO}

Usando de base as teorias de Giorgio Agamben (2004; 2007) e Michel Foucault (1985), pode-se concluir que dentro da lógica econômica mercadológica predatória o consumidor também é homo sacer e sua vulnerabilidade é, inclusive, paradoxalmente reconhecida pelo Direito e pela lei. ${ }^{12}$

Essa vulnerabilidade é exatamente um dos pilares do Direito do Consumidor, que no Brasil nasce de movimentos consumeristas que demandaram o nascimento e a positivação de uma proteção à parte

\footnotetext{
${ }^{11}$ Nota-se que durante a vigência do Estado nazista alemão, Hitler não realizou nenhum golpe de Estado, ele foi eleito e a suspensão da lei operada por ele decorria da aplicabilidade do art. 48, da Constituição de Weimar, em que "o presidente do Reich pode, caso a segurança pública e a ordem sejam gravemente perturbadas ou ameaçadas, tomar as decisões necessárias para o restabelecimento da segurança pública, se necessário com o auxílio das forças armadas. Com este fim pode provisoriamente suspender (ausser KraJt setzen) os direitos fundamentais contidos nos artigos 114, 115, 117, 118, 123, 124 e 153." (AGAMBEN, 2007, p. 174-175).

${ }_{12}$ A ideia de vulnerabilidade no direito está ligada à identificação de fraqueza ou debilidade de uma das partes da relação em consequência de condições ou qualidades que lhe são inerentes ou, ainda, de uma posição de força que pode ser identificada no outro sujeito da relação jurídica. (MIRAGEM, 2019.)
} 
vulnerável 13 das relações de consumo, "geração de normas, de políticas públicas, de órgãos fiscalizadores que proporcionem a correção de desvios nas práticas mercadológicas, que conduzem a resultados prejudiciais aos adquirentes de produtos e de serviços postos no mercado" (SCHMITT, 2014, p. 202), o que se concretizou com a Constituição Federal de 1988 que, mais do que instituir a promoção da defesa do consumidor enquanto garantia fundamental e princípio da ordem econômica, determinou também sua positivação através de um código, que surgiu no ordenamento jurídico brasileiro em 1990.

O Código de Defesa do Consumidor, assim, é sustentado pelo princípio da vulnerabilidade, "pedra angular das relações de consumo" (NUNES JUNIOR, 2008), como uma medida para compensar desigualdades "naturais", resultantes de fatos objetivos (idade, estado de saúde) ou "como resultado de uma situação voluntária instituída entre pessoas privadas (em relação às obrigações)" (FAVIER, 2013), de onde surge "a necessidade de proteção especial deste sujeito, individual ou coletivamente considerado no mercado brasileiro, como um corolário do princípio da dignidade da pessoa humana (art. $1^{\mathrm{o}}$, III da CF/88)" (MARQUES; MIRAGEM, 2008). A vulnerabilidade, assim, surge da possibilidade de que o consumidor seja lesado física, material ou moralmente no momento do consumo de um produto ou serviço, quando então não estará bem armado para enfrentar o fornecedor (CHAZAL, 2000, p. 244).14

\footnotetext{
${ }^{13}$ Ferrajoli destaca que a fim de estabelecer quais direitos devem ser garantidos como fundamentais, deve-se levar em conta quatro critérios: dignidade da pessoa, igualdade, tutela dos mais fracos e a paz. No que diz respeito à igualdade, o autor destaca que ela exige a "proteção das diferenças e a redução das desigualdades", impondo o respeito das diferenças através da garantia dos direitos sociais. Já no tocante à tutela dos mais fracos, ressalta que "todos os direitos fundamentais são (e se justificam enquanto) leis dos mais fracos em alternativa às leis dos mais fortes que vigorariam na sua ausência", afirmando que "todos os direitos fundamentais foram sancionados como o resultado de movimentos de luta ou de revolução que, de tempos em tempos, laceraram o véu de normalidade e naturalidade que ocultava uma precedente opressão ou discriminação". Parece-nos o caso do Direito do Consumidor, que surge num contexto de grande poderio econômico das empresas, criando a necessidade de igualar consumidores e fornecedores em condições de defesa de seus direitos. (FERRAJOLI, 2011, p. 104-106).

14 No original: Dans son activité de consommation, il peut subir une blessure corporelle à l'occasion de l'utilisation d'un bien défecteux. Il peut également subir une lésion pécuniaire, ce qui sera le cas le plus fréquent en pratique. Dans les deux
} 
Ainda que se aborde a vulnerabilidade como um conceito uno, a doutrina identifica, dentro das especificidades das relações de consumo, diversas classificações. Moraes (2009), em obra específica sobre o tema, identifica as vulnerabilidades técnica, jurídica, política ou legislativa, neuropsicológica, econômica e social, ambiental e tributária. Miragem (2019), Cavalieri Filho (2008) e Marques (2019) sustentam ainda existir a vulnerabilidade fática, que é a primeira vulnerabilidade do consumidor. Esta tem origem na "discrepância entre a maior capacidade econômica e social dos agentes econômicos (...) e a condição de hipossuficiente dos consumidores" (CAVALIERI FILHO, 2008, p. 39), focando-se no fornecedor, que "por sua posição de monopólio, por seu grande poder econômico ou em razão da essencialidade do serviço, impõe sua superioridade a todos que com ele contratam" (MARQUES, 2019).

A vulnerabilidade técnica, por sua vez, tem origem na falta de conhecimento do consumidor, se comparado ao fornecedor, sobre os produtos e serviços que consome, como o exemplo citado por Miragem (2019) da relação entre médico e paciente, em que aquele possui "informações científicas e clínicas que não estão ao alcance do consumidor leigo".

A vulnerabilidade jurídica, por sua vez (denominada por Marques de vulnerabilidade científica) decorre da falta de conhecimento do consumidor sobre "dos direitos e deveres inerentes à relação de consumo que estabelece, assim como a ausência da compreensão sobre as consequências jurídicas dos contratos que celebra" (MIRAGEM, 2019), bem como sua falta de experiência sobre economia e contabilidade, não tendo condições de compreender as consequências efetivas de seu consumo sobre seu patrimônio.

A vulnerabilidade política, por sua vez, está representada pela condição de debilidade dos consumidores, que enfrentam

cas, l'être vulnérable n'est pas tant l'être blessé, que celui qui peut l'être en raison de as faiblesse. (...) Si le consommateur doit être protégé par le droit, ce n'est pas parce qu'il est systématiquement lésé, mais parce qu'il n'est pas bien armé pour faire face à son partenaire-adversaire qu'est le professionnel. (tradução livre dos autores) 
fornecedores que exercem grande pressão sobre o Congresso Nacional e forçam a aprovação de leis que os fortalecem sempre mais e enfraquecem o consumidor. Ainda que haja bons exemplos de instituições de defesa dos consumidores, como o Brasilcon e o IDEC, estas não fazem frente ao poderio das grandes empresas.

A vulnerabilidade neuropsicológica é exemplificativa dos tempos atuais, em que a arquitetura nervosa dos consumidores é cada vez mais conhecida - e explorada. O fornecedor, assim, utiliza "todas as técnicas para aflorar necessidades, criar desejos, manipular manifestações de vontade e, assim, gerar indefinidas circunstâncias que poderão ter como resultado o maior consumo" (MORAES, 2009, p. 172).

A vulnerabilidade econômica e social decorre do desequilíbrio de forças entre as partes na relação de consumo, eis que os fornecedores "possuem maiores condições de impor a sua vontade àqueles, por intermédio da utilização dos mecanismos técnicos mais avançados que o poderio monetário pode conseguir" (MORAES, 2009, p. 175).

Já a vulnerabilidade ambiental surge quando os produtos e serviços oferecidos no mercado não informam seus potenciais (ou efetivos) riscos ao meio ambiente, que refletem na vida, saúde e segurança do consumidor (MORAES, 2009, p. 186).

Enfim, a vulnerabilidade tributária é representada pela implantação de tributos ilegais e inconstitucionais, nas palavras de Moraes (2009, p. 191), nas contas dos consumidores sob o pretexto de resolver "problemas de caixa".

Marques fala ainda da vulnerabilidade informacional, consequência da falta de informações sobre a produção dos bens de consumo, representando, segundo a autora, "o maior fator de desequilíbrio da relação de consumo" (MARQUES, 2019). Schmitt inclui ainda nessa modalidade as atividades publicitárias, que podem violar a liberdade de escolha do consumidor, eis que as técnicas utilizadas de forma massiva, "aliadas a mecanismos de convencimento 
e de manipulação psíquica, criam necessidades antes inexistentes, bem como representações ideais de situações de vida que induzem o consumidor a aceitá-las" (SCHMITT, 2014, p. 208).

Com a pandemia e a declaração do estado de calamidade pública, contudo, a vulnerabilização do consumidor, como aqui será apresentado, é potencializada pelas escolhas de governo que, diante da criação de um espaço anômico em face da crise sanitária, permite que os dispositivos consumeristas de proteção e defesa do consumidor, de ordem pública e interesse social, consagrados nos artigos $4^{\circ}$ e $5^{\circ}$ do Código de Direito do Consumidor sejam colocados em segundo plano.

Nesse contexto, a seletividade não declarada, quando a exceção se torna a regra, é (re)ativada pelo estado de calamidade pública que, mesmo sendo incapaz de suspender a Constituição, coloca aqueles que já são vulneráveis em uma zona ainda maior de nudez. Há, portanto, a convergência degradante de suspensão da ordem vigente que se faz sem poder ser, mas que tem por resultado asseverar, ainda mais, as debilidades na fruição de direitos por esses sujeitos.

Para compreender melhor a atual situação do Direito do Consumidor diante da pandemia de COVID-19, apresentam-se as principais alterações estabelecidas nesse período e como elas aumentam ainda mais a desigualdade de forças entre mercado e consumidores.

\section{OS NOVOS (E RUINS) MARCOS REGULATÓRIOS CONSUMERISTAS CRIADOS PELA PANDEMIA}

Indubitavelmente, um dos setores econômicos que mais sofreu com a crise sanitária de Coronavírus foi o da aviação e do turismo, com dados que informam cancelamento de $85 \%$ das viagens nesse período (ALESSI, 2020). Diversas medidas foram tomadas para o socorro de companhias aéreas, como a Medida Provisória n. 925/2020, que agora 
está em vias de se tornar lei (Projeto de Lei de Conversão 23/2020). A grande preocupação, dentre as diversas existentes nesse caso (sobre o tema veja por todos: SQUEFF; TARGA, 2020), é a alteração de critérios para a indenização por dano extrapatrimonial e as regulamentações tocantes ao reembolso de passagens aéreas canceladas por conta da Covid-19, que potencialmente irão de encontro aos interesses dos consumidores.

No primeiro ponto, relativo à indenização, ficará a cargo do consumidor a demonstração de falha de execução no serviço de transporte aéreo, devendo, igualmente, comprovar "prejuízo efetivo" e a sua extensão. No ponto subsequente, a nova regra dispõe uma série de novidades, como o marco temporal que compreende de 19 de março a 31 de dezembro de 2020 como prazo de reembolso, para voos cancelados, atrasados ou interrompidos por mais de 4 horas, abarcando as formas de aquisição de passagens por milhas, pontos ou crédito. Outra novidade é a possibilidade de substituir o reembolso: "Como substituição ao reembolso, o consumidor pode optar por receber um crédito de valor maior ou igual ao da passagem cancelada. O crédito pode ser usado pelo consumidor ou por um terceiro por ele indicado, num prazo de 18 meses" (SENADO, 2020).

Outro setor sensivelmente afetado foi o de serviços, de reservas e de eventos dos setores de turismo e de cultura. Em reação para tentar amenizar os efeitos econômicos nessas áreas, foi editada a Medida Provisória n. 498, de 8 de abril de 2020, que desobriga, sob determinadas condições, o reembolso dos valores pagos pelos consumidores relativos a esses serviços não prestados em razão da pandemia (PLANALTO, 2020). $\mathrm{O}$ art. $2^{\circ}$ dessa MP traz os requisitos permissivos para que o fornecedor se desobrigue à restituição imediata ao consumidor, de forma não cumulativa:

Art. $2^{\mathrm{o}}$ : Na hipótese de cancelamento de serviços, de reservas e de eventos, incluídos shows e espetáculos, o prestador de serviços ou a sociedade empresária não serão obrigados a reembolsar os valores pagos pelo consumidor, desde que assegurem:

I - a remarcação dos serviços, das reservas e dos eventos c ancelados; 
II - a disponibilização de crédito para uso ou abatimento $\mathrm{n}$ a compra de outros serviços, reservas e eventos, disponíve is nas respectivas empresas; ou

III - outro acordo a ser formalizado com o consumidor. (B RASIL, 2020).

O ponto a ser destacado em relação a esse regime jurídico transitório consta no inciso III, do referido artigo, porque dá a liberdade ao fornecedor de definir um "outro acordo" a ser formalizado, deixando de lado a presunção absoluta de vulnerabilidade dos consumidores, de modo que será de difícil percepção ao sujeito contratante mais débil identificar possíveis pontos contrários a seus direitos enquanto consumidores e até mesmo a imposição de onerosidades excessivas ou outras cláusulas arraigadas de abusividade, em desomenagem às vulnerabilidades informacionais, fáticas e técnicas. Conforme Falcão, "não se pode permitir que tamanha subjetividade da expressão 'outro acordo a ser formalizado' conceda indevida discricionariedade ao fornecedor quando da estipulação de um acordo sobre o modo como ocorreria o ressarcimento do consumidor pelos serviços cancelados" (FALCÃO, 2020).

Pode-se citar, por fim, o Regime Jurídico Emergencial (BRASIL, 2020a), que “dispõe sobre o Regime Jurídico Emergencial e Transitório das relações jurídicas de Direito Privado (RJET) no período da pandemia do coronavírus (Covid-19)". Referida lei trata de situações referentes a relações privadas de Direito Civil e Concorrencial, além de uma hipótese específica de Direito do Consumidor: o direito ao arrependimento em razão de compras efetuadas fora do estabelecimento comercial, tratando especificamente do delivery de produtos perecíveis ou de consumo imediato e de medicamentos.

Ora, sabe-se que desde o início da pandemia as notícias a respeito do setor de alimentação denotam quedas bruscas de faturamento. A Associação Brasileira da Indústria de Alimentos apurou que o setor experimentou "uma paralisação abrupta de 60\% de toda a cadeia produtiva por causa do coronavírus, desde os 
restaurantes até os distribuidores e a indústria” (GRANDI, 2020).

Em contrapartida, os setores de comércio eletrônico e entregas vislumbraram um crescimento na demanda. Segundo a quarta edição do Kantar Thermometer, que pesquisa os principais impactos socioeconômicos da pandemia no mundo, as compras online representaram uma experiência mais positiva do que a compra em lojas físicas para 54\% dos brasileiros (TERRA, 2020). A mesma pesquisa apontou que 54\% dos brasileiros têm escolhido o delivery para adquirirem alimentos prontos para o consumo, de 2 a 3 vezes na semana (TERRA, 2020), o que desde o início da pandemia vem sendo observado e apurado. Segundo o aplicativo Rappi, nas primeiras semanas após a chegada da pandemia ao país houve um crescimento de 300\% nos pedidos recebidos (SALOMÃO, 2020) e, de acordo com Bond (2020), após o primeiro mês de isolamento, as compras de alimentos por meio de aplicativos cresceram 30\% no país, havendo um aumento significativo entre consumidores com mais de 50 anos e entre as classes C, D e E.

Essa situação inesperada trouxe consigo algumas inconveniências, como relata o Procon do Estado de São Paulo, que afirma aumentado o número de denúncias e que boa parte delas dizem respeito a compras feitas pela internet, especialmente em razão de demora na entrega ou entrega não efetuada (BOND, 2020). No Dia dos Namorados, data extremamente lucrativa para o setor alimentício, muitos consumidores amargaram problemas de funcionamento dos aplicativos, especialmente com demora na entrega ou cancelamento de pedidos pelos fornecedores (APLICATIVO..., 2020).

A lei supracitada, assim, suspende até o final de outubro de 2020, a aplicação do art. 49 do Código de Defesa do Consumidor nas hipóteses supracitadas. Na prática, o consumidor que adquirir produtos perecíveis ou de consumo imediato e medicamentos e se encontre em uma situação em que deseja cancelar o pedido (seja por atraso, por não ter mais necessidade da aquisição ou simplesmente porque desistiu da compra, eis que o CDC não exige motivação para o 
exercício do direito de arrependimento) não poderá fazê-lo.

Ora, há situações em que o consumidor desiste de uma compra após a sua realização, especialmente quando esta ocorre em ambiente virtual, em que o acesso aos produtos se dá somente por uma tela e que não raras vezes é decorrente de uma publicidade ostensiva e sedutora. Ou, em outros casos, o tempo de entrega (ou seu efetivo descumprimento) torna o produto desnecessário ou indesejado.

O consumidor, no estado atual de pandemia, encontra-se definitivamente mais vulnerável no mercado, o que torna a atividade de comunicação comercial mais potente (SAMPAIO, 2020). Nesses casos, inviabilizar o exercício do direito de arrependimento é uma expressão simbólica das diversas medidas que vêm sendo tomadas desde o mês de março, e que têm como foco a proteção ao mercado em detrimento dos consumidores. Em um cenário em que as previsões mais otimistas são de um retorno aos níveis anteriores de consumo no segundo semestre de 2021 ou ainda em 2022 (GRANDI, 2020), as medidas adotadas deveriam proteger os consumidores, para que, ao final do estado de pandemia e retorno à nova normalidade, ainda exista um mercado capaz de consumir e fazer a economia retomar seu prumo.

Esses são apenas alguns exemplos de um enxame predatório da vulnerabilidade dos consumidores que se encontram ainda mais débeis durante a pandemia, seja por conta de constrições econômicas, seja sob quaisquer signos da vulnerabilidade, dando uma pela à vulnerabilidade psicológica, nesses casos, em que o medo e a insegurança impedem que se frua do contratado. Concorde-se com as conclusões de Squeff e Targa (2020): "justamente em virtude desta pandemia e do grande risco à saúde e à vida [...] é que se deve dar primazia aos seus interesses, que são [...] soberanos à luz do que prescreve a própria Constituição Federal brasileira”, como preconiza o tão conhecido art. $5^{\circ}$, XXXII, da CFRB/88.

Como já foi defendido, cabe enfatizar que o Código de Defesa do Consumidor, em sua plenitude, imbricado igualmente com normas esparsas relativas aos consumidores, é um instrumento capaz de 
Crise Pandêmica E A Violação Aos Direitos Dos Consumidores: Os Marcos...

enfrentar a crise econômica advinda da COVID-19 com foco na pessoacidadão-consumidor, posto que todos, em algum momento (se não sempre!) serão consumidores (MIRAGEM, 2019), primando pelo bem-estar da população brasileira e buscando o reaquecimento da economia de maneira saudável (MUCELIN; D’AQUINO, 2020), sem regimes jurídicos excepcionais que vulnerem, ainda mais, os vulneráveis.

\section{CONCLUSÃo}

A atual pandemia de coronavírus trouxe alterações significativas, não apenas no modo de vida das pessoas, mas na configuração dos diversos ramos do Direito. Novos marcos regulatórios foram criados e o Direito do Consumidor não se manteve alheio a isso.

A assunção de novos marcos regulatórios não é precisamente o principal problema, mas as escolhas postas nessas novas diretrizes é que são preocupantes.

Se, para superar os reveses econômicos gerados pela pandemia, opta-se por restringir direitos que arduamente foram conquistados, com a finalidade de garantir às empresas, que foram severamente prejudicadas com o isolamento social utilizado como medida de contenção da doença, sobrevida durante a crise, então, o alerta precisa ser ligado.

Em que pese haja propostas legislativas que tentem reequilibrar as relações de consumo, tentando encontrar uma convergência de interesses sem que isso signifique prejuízo substancial a nenhum dos agentes econômicos, como o Projeto de Lei que pretende instituir a moratória aos consumidores em contratos de consumo e essenciais 
(PL 1200/2020) (MARQUES; BERTONCELLO; LIMA, 2020), bem como os Projetos de atualização do Código de Defesa do Consumidor anteriores à pandemia, um relativo ao superendividamento das famílias, o PL 3515/2015, e outro ao comércio eletrônico, o PL 3514/2015, em atenção ao crescimento do e-commerce pelas dinâmicas impostas pelo distanciamento social, quarentena e congêneres (MUCELIN, 2020), o foco de proteção inverteu-se durante a pandemia, como demonstrado nas linhas anteriores.

Como visto, a separação entre exceção e regra são tênues. Walter Benjamin (2012) e Giorgio Agamben (2004; 2007) já denunciavam isso. A conjugação de medidas excepcionais de relativização de direitos num estado de exceção que sequer pode ser classificado como declarado desassossegam. Especialmente, quando a saída juridicamente construída para superar o momento caótico é a criação de um marco regulatório emergente do Direito do Consumidor que deixa, ainda que pontualmente, seus destinatários ainda mais desprotegidos, porque já o são nessa relação jurídica, e, precisamente, no momento em que mais necessitariam do abrigo da lei.

A criação dos novos (e ruins) marcos regulatórios emergentes do Direito do Consumidor são apenas um dos vários exemplos pelos quais o momento de crise pode ser utilizado para a suspensão da lei e que na fluidez provocada pela violência mantenedora pode, eventualmente, lesar de tamanha forma o edifício do Estado de Direito em que retornar ao que era antes seja, talvez, impossível. E, é sobre esse medo que se está a denunciar nessas breves linhas, de que a exceção aplicada aos direitos consumeristas se torne, finda a crise pandêmica, a regra. 
Crise Pandêmica E A Violação Aos Direitos Dos Consumidores: Os Marcos...

Data de Submissão: 31/07/2020

Data de Aprovação: 01/09/2020

Processo de Avaliação: double blind peer review

Editor Geral: Jailton Macena de Araújo

Editor de Área: Jailton Macena de Araújo

Assistente Editorial: Igor Barbosa B. G. Maciel

\section{REFERÊNCIAS}

AGAMBEN, Giorgio. Estado de Exceção e Genealogia do Poder.

Revista Brasileira de Estudos Políticos, Belo Horizonte, v. 108, p. 21-39, jan./jun. 2014.

AGAMBEN, Giorgio. Estado de Exceção. Trad. Iraci D. Poleti. São Paulo: Boitempo, 2004.

AGAMBEN, Giorgio. Homo Sacer: o poder soberano e a vida nua I. Belo Horizonte: Editora UFMG, 2007.

ALESSI, Gil. Número de viagens canceladas chega a 85\%, e entidade já fala em falência de empresas do setor. El País, 16 mar. 2020.

Disponível em: https://brasil.elpais.com/brasil/2020-0316/turismo-sofre-sua-maior-crise-com-coronavirus-e-taxa-decancelamento-de-viagens-chega-a-85.html. Acesso em: 23 jul. 2020.

APLICATIVO iFood cai na noite do Dia dos Namorados. Folha de São Paulo, 12 jun. 2020. Disponível em:

https://www1.folha.uol.com.br/mercado/2020/o6/aplicativo-ifoodcai-na-noite-do-dia-dos-namorados.shtml. Acesso em: 17 jul. 2020.

ARENDT, Hannah. Eichman em Jerusalém: um relato sobre a banalidade do mal. São Paulo: Companhia das Letras, 1999.

BELLONI, Luiza. Coronavírus impulsiona delivery no Brasil e muda rotina de restaurantes e consumidores. Huffpost, 21 mar. 2020. Disponível em: https://www.huffpostbrasil.com/entry/deliverycomida-coronavirus_br_5e6fcd76c5b63c3b6482a20a. Acesso em: 17 jul. 2020.

BENJAMIN, Walter. Crítica da Violência: crítica do poder. In: BENJAMIN, Walter. Documentos de cultura, documentos de barbárie: escritos escolhidos. Trad. Celeste H. M. Ribeiro de Sousa et. al. São Paulo: Cultrix - Editora da Universidade de São Paulo, 
1986. p. 160-175.

BENJAMIN, Walter. O anjo da história. Trad. João Barrento. Belo Horizonte: Autêntica, 2012.

BOND, Letycia. Compras por aplicativos têm alta de 30\% durante pandemia, diz pesquisa. Agência Brasil, 29 abr. 2020. Disponível em: https://agenciabrasil.ebc.com.br/economia/noticia/202004/compras-por-aplicativos-tem-alta-de-30-durante-pandemia-dizpesquisa. Acesso em: 18 jul. 2020.

BRASIL. Constituição da República Federativa do Brasil de 1988. Disponível em:

http://www.planalto.gov.br/ccivil_o3/constituicao/ConstituicaoCo mpilado.htm. Acesso em: 13 dez. 2019.

BRASIL. Decreto n. 7257, de 4 de agosto de 2o10. Disponível em: http://www.planalto.gov.br/ccivil_03/_ato20072010/2010/Decreto/D7257.htm. Acesso em: 21 mai. 2020.

BRASIL. Lei n. 14.010, de 10 de junho de 2020. Disponível em: http://www.planalto.gov.br/ccivil_03/_ato20192022/2020/lei/L14010.htm. Acesso em: 17 jul. 2020.

BRASIL. Lei n. 8.078, de 11 de setembro de 1990. Disponível em:

http://www.planalto.gov.br/ccivil_03/leis/L8078compilado.htm. Acesso em: 17 jul. 2020.

BRASIL. Medida Provisória n. 925/202o, de março de 2020. Planalto. Disponível em:

https://www.camara.leg.br/proposicoesWeb/prop_mostrarintegra?c odteor $=1869759 \&$ filename $=$ MPV $+925 / 2020$. Acesso em: 17 jul. 2020.

BRASIL. Medida Provisória n. 948, abril de 202o. Planalto. Disponível em: <http://www.planalto.gov.br/ccivil_03/_Ato20192022/2020/Mpv/mpv948.htm >. Acesso em: 01 maio 2020.

BRASIL. Projeto de Lei n. 1179, de 2020. Disponível em: https://legis.senado.leg.br/sdleggetter $/$ documento $? \mathrm{dm}=8081779 \&$ ts $=1594025237138 \&$ disposition $=$ in line. Acesso em: 17 jul. 2020.

CARVALHO, Kildare Gonçalves. Direito Constitucional. 18 ed. rev. atual. ampl. Belo Horizonte: Del Rey, 2012.

CAVALIERI FILHO, Sergio. Programa de Direito do Consumidor. São Paulo: Atlas, 2008.

CHAZAL, Jean-Pascal. Vulnérabilité et droit de la consommation. In: COHET-CORDEY, Frédérique. Vulnérabilité et droit: le 
Crise Pandêmica E A Violação Aos Direitos Dos Consumidores: Os Marcos...

développement de la vulnérabilité et ses enjeux en droit. Grenoble: Presses Universitaires de Grenoble, 2000. p. 243-264.

DERRIDA, Jacques. Força de lei: o fundamento místico da autoridade. Trad. Leyla Perrone-Moisés. São Paulo: WMF Martins Fontes, 2007.

FALCÃO, Rebeca. MP nº 948/2020 e os efeitos da Covid-19 para o consumidor. Conjur, 22 abr. 2020. Disponível em:

https://www.conjur.com.br/2020-abr-22/rebeca-falcao-mp-948efeitos-consumidor\#_ftn1. Acesso em: 15 jul. 2020.

FAVIER, Yann. A inalcançável definição de vulnerabilidade aplicada ao Direito: abordagem francesa. Revista de Direito do

Consumidor, São Paulo, v. 85, p. 15 e ss., jan. 2013.

FERRAJOLI, Luigi. Por uma Teoria dos Direitos e dos Bens

Fundamentais. Porto Alegre: Livraria do Advogado, 2011.

FOUCAULT, Michel. História da sexualidade I: A vontade de saber. Tradução de Maria Thereza da Costa Albuquerque e J. A. Guilhon Albuquerque. 7 ed. Rio de Janeiro: Edições Graal, 1985.

GRANDI, Guilherme. Mercado de restaurantes pós-pandemia será menor, mas mais competitivo e estruturado. Gazeta do Povo, 07 maio 2020. Disponível em:

https://www.gazetadopovo.com.br/bomgourmet/mercado-esetor/mercado-restaurantes-competitivo-pos-pandemia/. Acesso em: 17 jul. 2020.

HOBBES, Thomas. Leviatã: ou a matéria, forma e poder de um Estado eclesiástico e civil. Trad. Rosina D’Angina. São Paulo: Martin Claret, 2009.

MARQUES, Claudia Lima. Contratos no Código de Defesa do Consumidor: O novo regime das relações contratuais. 9. ed. São Paulo: Revista dos Tribunais, 2019. [e-book]

MARQUES, Claudia Lima; BERTONCELLO, Karen; LIMA, Clarissa Costa de. Exceção dilatória para os consumidores frente à Força maior da pandemia De COVID-19: pela urgente Aprovação do PL 3.515/2015 de atualização do CDC e por uma moratória aos consumidores. Revista de Direito do Consumidor, São Paulo, v. 129, p. 47-71, maio/jun. 2020.

MARQUES, Claudia Lima; MIRAGEM, Bruno. O direito fundamental de proteção do consumidor e os 20 anos da Constituição:

fundamentos e desafios do direito do consumidor brasileiro contemporâneo. In: MARTINS, Ives Gandra; REZEK, Francisco (coords.). Constituição Federal: avanços, contribuições e modificações no processo democrático brasileiro. São Paulo: Revista 
dos Tribunais, 2008. p. 644-667.

MARQUES, Claudia Lima; MIRAGEM, Bruno. O novo direito privado e a proteção dos vulneráveis. São Paulo: Revista dos Tribunais, 2012.

MIRAGEM, Bruno. Curso de Direito do Consumidor. 6. ed. São Paulo: Revista dos Tribunais, 2019. [e-book]

MORAES, Paulo Valério Dal Pai. Código de Defesa do

Consumidor: o princípio da vulnerabilidade no contrato, na publicidade, nas demais práticas comerciais: interpretação sistemática do direito. 3. ed. Porto Alegre: Livraria do Advogado, 2009.

MUCELIN, Guilherme. Conexão online e hiperconfiança: os players da economia do compartilhamento e o direito do consumidor. São Paulo: RT, 2020.

MUCELIN, Guilherme; D'AQUINO, Lúcia. O papel do direito do consumidor para o bem-estar da população brasileira e o enfrentamento à pandemia de COVID-19. Revista de Direito do Consumidor, São Paulo, v. 129, p. 17-46, abr./jun. 2020.

NUNES JUNIOR, Vidal Nunes. A publicidade comercial dirigida ao público infantil. In: MARTINS, Ives Gandra; REZEK, Francisco (coords.). Constituição Federal: avanços, contribuições e modificações no processo democrático brasileiro. São Paulo: Revista dos Tribunais, 2008. p. 842-846.

SALOMÃO, Karin. iFood e Rappi: mais entregadores (e mais cobrança por apoio) na pandemia. Exame, 18 abr. 2020. Disponível em: https://exame.com/negocios/coronavirus-leva-maisentregadores-e-gorjetas-aos-apps-de-delivery/. Acesso em: 16 jun. 2020.

SAMPAIO, Marília de Ávila e Silva. A suspensão do direito de arrependimento do artigo 49 do CDC. ConJur, 17 jun. 2020. Disponível em: https://www.conjur.com.br/2020-jun-17/garantiasconsumo-suspensao-direito-arrependimento-cdc. Acesso em: $17 \mathrm{jul}$. 2020.

SANTOS, Aricê Moacyr Amaral. O Estado de Emergência. São Paulo: Sugestões Literárias, 1981.

SCHMITT, Carl. La Dictadura: desde los comienzos del pensamiento moderno de la soberanía hasta la lucha de clases proletaria. Trad. José Diaz García. Revista de Occidente: Madrid, 1968.

SCHMITT, Carl. Teologia Política. Trad. Luiz Moreira. Belo Horizonte: Del Rey, 2006. 
Crise Pandêmica E A Violação Aos Direitos Dos Consumidores: Os Marcos...

SCHMITT, Cristiano Heineck. Consumidores hipervulneráveis: a proteção do idoso no mercado de consumo. São Paulo: Atlas, 2014.

SENADO NOTÍCIAS. Senado tem uma semana para votar MP de ajuda ao setor aéreo. Agência Senado, 09 jul. 2020. Disponível em: https://www12.senado.leg.br/noticias/materias/2020/07/o9/senad o-tem-uma-semana-para-votar-mp-de-ajuda-ao-setor-aereo. Acesso em: 20 jul. 2020.

SILVA, José Afonso da. Curso de Direito Constitucional Positivo. São Paulo: Editora Malheiros, 37 ed. rev. atual., 2014.

TARGA, Maria Luiza Baillo; SQUEFF, Tatiana Cardoso. Os direitos dos passageiros-consumidores de transporte aéreo em tempos de pandemia. Revista de Direito do Consumidor, São Paulo, v. 129, p. 73-109, abr./jun. 2020.

TERRA, Thiago. Pandemia gera aumento de demanda por delivery no Brasil, diz pesquisa. Mundo do Marketing, 20 abr. 2020.

Disponível em: https://www.mundodomarketing.com.br/ultimasnoticias/38627/pandemia-gera-aumento-de-demanda-por-deliveryno-brasil-diz-pesquisa.html. Acesso em: 16 jul. 2020.

WERMUTH, Maiquel Ângelo Dezordi; CORREIO, Joice Graciele Neilsson. O Campo como Espaço da Exceção: uma análise da vida nua feminina nos lares brasileiros à luz da biopolítica. Prima Facie. João Pessoa, v. 15, n. 30, p. 01-34, maio 2017. Disponível em: https://periodicos.ufpb.br/index.php/primafacie/article/view/3308 4/17576. Acesso em: 27 ago. 2020. 


\title{
Pandemic Crisis And Violation Of Consumers Rights: The Regulatory Frameworks Emerging From Consumer Law
}

\author{
Lúcia Souza d'Aquino
}

Luana Mathias Souto

Guilherme Mucelin

\begin{abstract}
This study seeks to reflect on the impacts of the emergency regulatory framework created to consumer relations, which were severely shaken by social isolation, anchored in a bibliographic review on the topic, and dialoguing with data related to the current scenario imposed by the pandemic of COVID-19 on consumer relations. Based on the analysis of the regulatory frameworks created to these relations, the factuality of the theory of the state of exception, developed by Giorgio Agamben (2004; 2007), was observed when the choices promoted to reverse the harmful effects of the pandemic, benefits only one of the poles of consumer relationship and that, consequently, weakens consumers, even more, opening up their conditions as sacred men, bare lives of rights. The reflection presented here, finally, lead to the conclusion that the pandemic of COVID-19 and the new regulatory frameworks of Consumer Law created by it only enhance the vulnerabilities of those who are already, under the different points of view presented in this study, vulnerable.
\end{abstract}

Key-words: COVID-19. State of exception. Consumer Law. Vulnerability.

DOI: https://doi.org/10.22478/ufpb.1678-2593.2020v19n42.54271

Conteúdo sob licença Creative Commons: Attribuition-NonCommercial-NoDerivative 4.o International (CC BY-NC-ND 4.0) 